\title{
EXPLORING THE ROLE OF THE HUMAN RESOURCE FUNCTION IN THE SOUTH AFRICAN INFORMATION TECHNOLOGY INDUSTRY
}

\author{
CARON HALL \\ LINDA FOURIE \\ Programme in Industrial Psychology \\ Department of Human Resource Management \\ University of Johannesburg \\ lfourie@uj.ac.za
}

\begin{abstract}
The Information Technology (IT) industry is one that is characterised by rapid change and a heavy reliance on human skills. A study was conducted to qualitatively explore the role of the Human Resource (HR) function in the South African IT industry. Semi-structured individual and focus group interviews with professionals in this function highlighted many opportunities for HR to render a more strategic role in an environment where a skills shortage and many related problem areas exist. The implications of these findings are discussed and proposals for redefining the role of HR in the specific industry are offered.
\end{abstract}

Key words

Changed role of HR, HR in IT industry, challenges of the HR practitioner

Prior to the 1970's the Human Resource (HR) function existed primarily as an administrative and transactional function (Gaines-Robinson \& Robinson, 2005). As the business environment changed and people issues became more complex, expectations of the HR function also changed. Today, businesses are dealing with the challenges of globalisation, value-chains, profitability, organisational transformation, technology and the attraction and retention of intellectual capital (Ulrich, 1997). They are operating in a more complex, competitive and challenging environment (Gaines-Robinson \& Robinson, 2005). Change is constant and increased uncertainty has resulted in a new set of dynamics emerging in organisations (Wheatley, 2003). Organisations can no longer easily predict the future and therefore have to focus on the capabilities and competencies that lead to adaptability (Hosking, 2006). Companies are faced with changing demographics as the workforce ages and becomes more diverse (MacDonald, 2003) and the generation gap poses a challenge as each age group exhibits differences in motivation, communication styles and work values (Kaye, Scheef \& Thielfoldt, 2003). The nature of the employment relationship is in itself continuously changing, with conventional employment contracts being replaced by temporary, contract and projectbased work (Sartain, 2003).

Within such a complex and continuously chancing environment HR is well positioned to assist organisations in dealing with these challenges. HR practices can enhance an organisation's competitive advantage (Boudreau \& Ramstad, 2003) by specifically focusing on the retention, optimisation and competitiveness of talent or human capital, and by managing organisational change (Lawler, Ulrich, Fitz-enz \& Madden, 2004; Ulrich, 1997). However, this requires traditional HR to change its focus and consider what it actually does, what it delivers to the organisation, how it adds value and how it may measure its contribution to business results (Ulrich, 1997). HR outputs and business strategy should be closely aligned, which implies a need for HR professionals to understand the business, its needs and strategies, and even its market or shareholder value (Ulrich \& Smallwood, 2003). True HR transformation arises when HR is able to add value not only to staff, but also to customers and shareholders (Ulrich \& Brockbank, 2005). These new demands mean that HR can no longer function as a back-office support function, but rather as a key contributing partner; in a leadership capacity, in its own right.
Many models have been proposed of what the new, redesigned HR function and its associated roles should look like. A key role evidenced in the literature is that of $\mathrm{HR}$ as a strategic business partner. This role implies an active involvement in and understanding of business and strategic issues, and an alignment of HR, business and strategic goals (Ulrich, 1997). It also involves developing credibility and trust with organisational leaders, identifying and supporting strategic projects and focusing on long-term organisational needs (Gaines-Robinson \& Robinson, 2005). At a less strategic level, HR also needs to partner with line management to deliver an end result that is a unique combination of HR and line contributions (Ulrich, 1997). HR should coach managers to improve their people skills, empowering them to deal with their own people issues (Hunter \& Saunders, 2005). This role has been taken a step further to the point where HR professionals act as creators or drivers of the business, understanding both internal and external stakeholders (Ulrich \& Brockbank, 2005).

Another key focus of the new HR function is that of change management. HR is required, with management, to overcome obstacles to change, sustain change, and improve teamwork and productivity (Lawler et al., 2004). They need to help set strategic direction, ensure decisions are made timeously, and ensure that resource systems provide adequate support. HR should also engage all stakeholders and gain their commitment to ensure that the implementation of strategic initiatives is successful (Brockbank, 2003).

The proposed models differ in their view of HR's administrative role. Some see it as essential in the delivery of an efficient support function (Ulrich, 1997) whilst others advocate the removal or reduction of administrative and transactional functions through the use of outsourcing services and technology (Gaines-Robinson \& Robinson, 2005). The latter requires an improvement in HR technology skills and the ability to choose technology that contributes to overall efficiency and competitiveness (Fletcher, 2005). There is a counter-argument to outsourcing that argues that it distances HR from employees. There are also issues pertaining to the quality of outsourced services. As a result, many companies are bringing outsourced functions, such as recruitment, back inhouse (Business Day, 2005).

It is obvious that in order to fulfill any of these proposed new roles, HR professionals will need to develop a new set of skills, 
capabilities and competencies (Jeffay \& Bicos, 2003). They firstly need to manage their own change and be able to adapt to constantly changing circumstances (Henson, 2005). They further need to develop the capabilities of speed, implementation, innovation and integration (Ulrich, 1997). They require customer relationship management skills that are crucial in delivering solutions that add value to the organisation (Hunter \& Saunders, 2005). They need not only generic consultancy skills, but also specific project management skills, along with the ability to be creative and flexible (Green, 2002). Skills in the areas of finance, business understanding, cultural sensitivity and negotiation are also required (Bear, 2004). Despite all these required changes, HR still needs to retain focus on its primary function, namely that of human resource management. These professionals still need to own, maintain, and keep abreast of an HR body of knowledge that defines best practices and solutions for HR issues, thereby making them experts in their field (Ulrich \& Brockbank, 2005).

Despite the deliberations on what HR should deliver, look like, and what skills are needed, HR transformation is in fact rare (Lawler et al., 2004). While the shift to a more strategic function is conceptually easy, it is far more difficult to implement on a day-to-day basis. Members of the traditional HR community may also not be able to make the transition and, as a result, it is postulated that this community is likely to shrink by $40 \%-50 \%$ (Hunter \& Saunders, 2005). There are also questions pertaining to HR's developmental routes, which have not changed to fit the new HR requirements (Hunter \& Saunders, 2005). For this reason there is an increasing trend to bring in skilled operational professionals, with no HR experience, to build operational capability within the HR function. Technology, furthermore, which could serve as a transformation enabler, often has a high cost and companies are reluctant to spend money in this area, as it is regarded as a non-critical expense. The result is that HR appears trapped in its traditional role. The need for a changed HR function and associated new roles are apparent. Yet, there appears to be conflict between the need for change and the actual implementation thereof. Theoretically it is clear where HR should be aiming, yet implementation of these changes in practice is problematic. Whilst it is acknowledged that HR professionals are at an important cross-roads (Lawler et al., 2004), there is speculation as to whether the function truly adds value and whether it is actually necessary at all (Van der Westhuizen, Van Vuuren \& Visser, 2003).

It is against the above-mentioned background that this study was undertaken to determine what roles HR professionals currently fulfill - specifically within the Information Technology (IT) industry in South Africa - with the intention to propose a redefinition of these roles to suit current needs and challenges. Since it is an industry subject to rapid change and technological advances, and at the same time heavily reliant on human skills (or 'intellectual capital') it was argued that HR had a meaningful role to play within the industry, provided that it had adapted itself to the particular needs and challenges of the industry. In this respect note was taken of the view that the role of HR as a strategic or business partner is likely to be even more evident in so-called high-tech companies (Business Day, 2005).

Globally the IT industry experienced a period of rapid change and growth during the period $1999-2000$ (Lessard \& Baldwin, 2003), specifically in the area of Internet-based, or 'dot-com', companies. IT share prices grew phenomenally reaching all time share price highs. However, many of the so-called 'dot-com' companies lacked supporting technology and their business plans and models had no solid base. Not surprisingly, in 2001, many of these companies failed and took many of the established IT vendors with them. As a result, a period of restructuring and focus on earnings ensued and many IT companies were forced to consolidate, downsize and retrench. From 2004 onwards the industry has once again exhibited signs of growth, with a current growth rate of $8,5 \%$ per annum
(Burrows, 2006). Yet, it is still faced with many challenges. In South Africa specific challenges exist. For one, the advent of a second network operator will require vast IT skills and services in an industry that is widely believed to be characterised by a skills shortage. In addition, Black Economic Empowerment (BEE) and the proposed Information and Communication Technology (ICT) Charter - which is intended to provide a Code of Good Practice for the transformation of the IT industry - poses a big challenge, specifically to multinationals, who are unwilling to sell ownership and who may consider disinvestment as a result. Against this background a debate also rages as to whether the above-mentioned skills shortage, presumably caused by rapid technological changes and increased specialisation (Burrows, 2005), actually exists. Some argue that the skills are available, but the need to find previously disadvantaged staff in a traditionally white male industry is forcing companies to disregard white males, who have the required skills (Burrows, 2006). Whether true or not, in a buoyant recruitment market, companies are continually required to invest more and more in their staff, whilst always facing the danger that their highlyskilled staff (especially those from designated groups) will be headhunted by the opposition (Burrows, 2005). IT staff are also becoming more selective in terms of which companies they work for and companies are required to be more creative in terms of gaining and retaining their 'intellectual capital' (Gqubule, 2006).

From the above it was apparent that the IT industry was subject to many of the changes prevalent in the business world at large, and it was hoped to reveal through this study findings that could assist both the industry and HR professionals to re-invent and reposition HR within this industry to optimise its contribution, both at a strategic and a change management level. The following research question was consequently formulated: How do HR professionals in the IT industry view their work, with specific reference to the challenges that they experience? Through the insights gained from these professionals it was hoped to provide some guidelines to inform the required changes and possible realignment of HR.

\section{RESEARCH DESIGN}

\section{Research approach}

A research approach was chosen that would allow for HR professionals in the IT industry to openly share their personal experiences of the challenges that they face in their work. This was in line with our own scientific beliefs, or ontology, as to the nature of social phenomena, supporting a social constructionist point of view. We believe that perceptions of HR in the IT industry are continually being created by the actors within it. We wanted to uncover what the individual participants believed their own challenges to be and wanted to understand how they understood and experienced their specific circumstances. The study was explorative in nature, and therefore a broadly qualitative research approach was chosen. A quantitative approach was rejected as it was felt that the variables under consideration, namely the challenges HR faces (and the roles they fulfill in this regard) were probably too broad to be made quantifiable without breaking them down into much smaller, precise components; the focus was particularly on the broader, higher-level roles. A mixed approach using both quantitative and qualitative approaches could have been applicable, yet was rejected as it would have been too extensive and time intensive, given the scope and purpose of the study.

In terms of our epistemology, we aimed to gain an understanding of the challenges and roles of HR professionals operating in the South African IT sector by using unstructured, flexible methods (Burden, 2006). The intention was to collect "thick and rich descriptions" (Rubin \& Rubin, 1995, p. 34) from participants to guide our understanding and interpretation of 
the information gained from them. Such a relatively unstructured and flexible research approach was deemed appropriate because of its naturalistic perspective and its focus on an interpretive understanding of human experience (Denzin $\&$ Lincoln, 2003). The paradigm of enquiry within which this research was undertaken can therefore be described as interpretive.

Schurink (2003) described the interpretive (and related constructivist paradigms) as focusing on "particular situated actors" who are made up of "events and phenomena through long-lasting processes of interaction that include history, language and action". It was pre-supposed that the research participants had a shared "social reality" that had been "built up over time" through a "shared history, experience and communication" of being in the IT industry specifically.

A case study design was employed since it can be regarded as a building block for data collection frequently associated with qualitative research (Burton, 2000). According to Babbie and Mouton (2005) a case study design facilitates an intensive investigation of a single unit which can be an individual case study, community studies, social group studies, studies of organisations and institutions, studies of events, roles and relationships, and studies of countries and nations. This study implied an in-depth investigation of members of a social group (HR professionals) all employed within the same organisational context (IT industry). In order to overcome the issue of 'representativeness', multiple participants from different organisations in the IT industry were used to make the case study "more compelling and more robust" (Burton, 2000, p. 224).

\section{Methodology}

Methods of data collection included interviewing and strategies of enquiry included grounded theory. Data gathering through interviewing rather than through questionnaires was chosen to enable participants to reflect upon issues that were pertinent to themselves, and to do so at length. It was also felt that talking, rather than having to write anything down, would make the flow of information more natural and uninhibited. Information given in an interview could also be clarified and further elaborated upon, if necessary. An interview also provided an opportunity to give participants feedback and personal assurance about the way in which the information would be used. The interviews were semi-structured as we had a specific topic that we wanted to explore, and had limited time within which to do so. The interview was deliberately guided in the direction of the topic through the use of preplanned questions. Both individual and focus group interviews were conducted.

\section{Participants}

A non-probability purposive sampling strategy was followed specifically targeting HR professionals operating in the South African IT sector who we believed most likely to give the "greatest possible insight" into the research topic (Esterberg, 2002). The sampling was done from the participants in the annual Watson Wyatt IT industry salary survey. This survey has 40 participating companies, all of whom operate in the South African IT sector. The survey was initially established in the early 1990 's as a small focus group for hardware companies, to benchmark common jobs and compare salary packages. The focus group was eventually extended to include software companies, and in 1996, Microsoft facilitated the introduction of global survey administrators, Watson Wyatt, to manage and distribute the survey. Since 2002 a local company, LMO Services, has been administrating the survey in association with Watson Wyatt. The information provided by the survey is used by participating companies as the basis for their remuneration plans and strategies. (One of the researchers has personally participated in the Watson Wyatt survey, and can therefore be regarded as an 'insider').
An initial e-mail was sent out to all the potential HR participants, inviting participation. This was followed with telephonic requests for interviews. Ten companies agreed to participate in the research study and, in all cases, interviews were held with either the HR Director or HR Manager, or the most senior HR person in the organisation. A breakdown of the participant sample appears in Table 1.

TABLE 1:

\section{RESEARCH PARTICIPANTS}

\begin{tabular}{|c|c|c|c|c|c|c|}
\hline \multirow{2}{*}{$\begin{array}{l}\text { Com- } \\
\text { pany }\end{array}$} & \multirow[t]{2}{*}{ Ownership } & \multirow[t]{2}{*}{ Job title } & \multicolumn{3}{|c|}{$\begin{array}{c}\text { Years } \\
\text { experience }\end{array}$} & \multirow[t]{2}{*}{$\begin{array}{l}\text { Qualifi- } \\
\text { cations }\end{array}$} \\
\hline & & & $\begin{array}{l}\text { Current } \\
\text { position }\end{array}$ & HR & $\begin{array}{c}\text { IT } \\
\text { industry }\end{array}$ & \\
\hline 1 & Multinational & HR Manager & 5 & 8 & 6 & Hons \\
\hline 2 & SA & Group Executive: HR & 14 & 34 & 14 & $\mathrm{PhD}$ \\
\hline 3 & Multinational & HR Manager & 25 & 38 & 25 & MCom \\
\hline 4 & SA & $\begin{array}{l}\text { Group HR \& } \\
\text { Transformation Mngr }\end{array}$ & 5 & 25 & 10 & MA \\
\hline 5 & Multinational & $\begin{array}{l}\text { Senior HR Manager: } \\
\text { Africa }\end{array}$ & 4 & 19 & 9 & MCom \\
\hline 6 & Multinational & HR Director & 1.5 & 12 & 3 & Diploma \\
\hline 7 & Multinational & HR Manager & 6,5 & 8 & 6,5 & MA \\
\hline 8 & SA & HR Manager & 1 & 4 & 6 & MA \\
\hline 9 & Multinational & HR Generalist & 20 & 20 & 22 & Diploma \\
\hline 10 & Multinational & HR Consultant & 2,5 & 5 & 2,5 & Hons \\
\hline
\end{tabular}

\section{Procedure}

Pre-interview preparation involved sending an e-mail to participants confirming the date, time and venue agreed to earlier. Seven individual and two focus group interviews were conducted. Participants' rights to privacy were acknowledged and each participant was given a clear explanation of the research purpose, as well as the research process to be followed during the interview. As an industry 'insider', and in some cases competitor, this was particularly relevant to reassure the participants that confidentiality would be maintained.

A first pilot interview was conducted and the following two open-ended questions were posed:

- What are the major challenges facing you as an HR professional operating in the South African IT industry?

- What is the effect of this on your HR function?

The richness of data that was solicited during this first pilot interview was deemed acceptable. However, the single participant was so forthcoming about personal experiences pertaining to the topic - which we regarded as both relevant and a source of rich data - that it was decided to include a third question for purposes of the subsequent interviews:

- What is the effect of all of this on you personally?

All the interviews were recorded by means of an electronic recording device, transcribed verbatim and stored in a secure location.

\section{Data analysis}

The process of data analysis was approached with the intention of "bringing order, structure, and interpretation to the mass of collected data" (Marshall \& Rossman, 1999, p. 150). Interview data was analysed by means of strategies appropriate within a grounded theory approach, as suggested by Strauss and Corbin (1990). Manual, open-coded, thematic content analysis was used as main procedure (see Berg, 1995; Mouton, 2001) to reduce the initial bulk of data to workable proportions. Axial coding was then deployed to connect the open codes into broader themes or categories. These categories were determined inductively, by immersion in the data, and by grounding these in the data 
through specific data excerpts. Finally, the axial codes were organised into three core themes on the basis of conceptual similarity or congruence (Babbie \& Mouton, 2005). Themes were defined and interpreted using (1) personal experience as Human Resources professionals and (2) the theoretical knowledge acquired during formal academic studies in industrial psychology. This posed specific challenges in that closeness to the topic could, at the same time, act both as a threat and an opportunity for informed insights. Special care was taken, therefore, to remain rigorous, focused, professional and reasonably objective.

The coding process was started by going through each transcribed interview and identifying key words, phrases and sentences. These were then placed onto a chart and data from each subsequent interview was added to the same chart. After all the individual interviews had been conducted, coloured markers were used on the chart to identify areas of commonality. These identified areas were then transferred onto a spreadsheet, given category names and divided into broad themes.

Once the data from the individual interviews had been coded and categorised, the themes were presented to the two focus groups in a visual format. Care was taken to not have direct competitors together in the same focus group, as this could have restricted their conversation. Each group was asked to comment on the relevance and commonality of the findings based on their own experiences, which allowed the opportunity for further exploration of any emerging perspectives. The discussions were again recorded and transcribed in full. An observer or note-taker was not deemed necessary due to the small number of participants in each group. However, field notes were made after each interview.

\section{Ethical considerations}

In congruence with both the ethical position generally held by social science research communities, and the University of Johannesburg, Faculty of Management's ethical guidelines for conducting research, an informed consent form for all participants (explaining the purpose of the research, the arrangement that information would be recorded, and that all information would remain confidential) was drafted. The informed consent form was signed by both parties prior to any data being recorded.

With reference to the quality of the research endeavour it was accepted that qualitative research does not address issues pertaining to reliability and validity in the same manner as quantitative research; it is rather more concerned with the notion of trustworthiness, which can generally be addressed through the concepts of credibility, transferability, dependability and confirmability (Babbie \& Mouton, 2005). A number of strategies were employed to enhance the quality of the research in line with the above criteria. These included (1) the use of both individual and focus group interviews to enhance data triangulation, (2) the continuation of the data collection process until it was felt that a point of saturation had been reached, (3) the keeping of field and methodological notes (consisting of code notes, actual coding products, and theoretical notes to explore the inductive reasoning behind the category formation) and (4) the use of a peer debriefing process by submitting an initial draft of this report to a colleague in the industry (who had recently completed his doctoral thesis and whose suggestions were incorporated into the final document). In addition, the criterion of transferability was addressed, firstly, through the use of purposive sampling methods and, secondly, through the use of "thick" (Babbie \& Mouton, 2005, p. 277), detailed descriptions of the research setting, context and process. A confirmability audit trail was created through the storage of all data, as well as all field, methodological and theoretical notes in a systematic hard copy file.
The individual interviews were conducted over the period February to April 2006, and the focus group interviews took place in July 2006 , making the total period of data gathering six months. Industry changes were monitored during this time, but none were perceived to have any significant impact on individual responses. The above process of data analysis rendered the following findings.

\section{FINDINGS}

The process of open-coded, thematic data analysis described above, led to the identification of three core themes: (1) Industry-specific organisational challenges, (2) role of HR and (3) effect of HR roles on individuals in HR.

\section{Theme 1: Industry-specific organisational challenges}

Within this first core theme, three sub-themes, each consisting of a number of related open codes, were identified. These three sub-themes related to (1) the nature of the industry, (2) attraction and retention of staff and (3) strategic requirements for HR.

\section{Nature of the industry}

The IT industry was referred to as a fast, aggressive industry. It was described by the participants as one of rapid change, aggressive targets and fierce competition, a dynamic industry that can be exciting and challenging to be in: "... a fast, very fast paced industry...very high targets, very high expectations", "You've got to be faster, quicker, you've got to be more dynamic...you've got to be cleverer than your opposition", "... it's a new, fairly new industry and it's exciting and it's sexy". It was further described as profit and budget driven, with a strong focus on profits and budgets that are strictly controlled: "... single-minded focus on business profit", "We are expected to conquer the world with no budget". The industry was further characterised by a lack of focus on people. There was a perception that the participants' organisations are not focused on people and people management: "There's no people management going on", "I think people bandy around the idea of people being the most valuable asset ... but I don't think in the South African context we do particularly well in that context". Stress and burnout were identified as a further feature of the industry. The pace of work and the high incidence of change within organisations were perceived as having a negative effect on the people within it: "... so the pressure is tremendous on the people ... one of the reasons why we lose them, they can't keep up the pace, it's not possible for any person", "It takes convincing, it takes reason, and it takes a will on the part of people to change, but I think people do get a little bit to the point where they get battle and change weary", "Burnout is a huge issue". High performance expectations were identified as a fifth feature of the IT industry. The need for high performance also means adopting a hard approach to performance management, where unsatisfactory performance is not tolerated: "If they don't perform they're out", "You've got this needs improving kind of element, so there's that kind of almost like a wash-out". Combining all the above features produced a first axial code that characterised the South African IT industry as a fast, aggressive industry where monetary considerations are paramount, high performance expectations exist, and employees are relatively uncared for.

\section{Attraction and retention of staff}

Further analysis of the data produced a second sub-theme concerned with the attraction and retention of staff. Five related open codes have reference. The first open code referred to a perceived skills shortage. The market is viewed as being relatively small in terms of the skills that are available and the demand for skills is clearly outweighing the supply, creating a fiercely competitive market: "I think the market is very small", "There are more and more of our competitors wanting the same kind of people ... the demand is higher than the supply", "It's an industry where there's lots of mobility, while you have limited capacity of 
skills that are available in the market ... retention becomes a key challenge", "... war on talent, war for talent ... they are all fighting for the same people".

The second open code referred to the notion of discerning employees. Exacerbating the perceived skills shortage is the fact that individuals within the sector are also becoming more discerning, requiring companies to do more than just the usual to retain and attract staff: "People are more demanding in terms of career development and we need to keep on doing better things to try and keep people", "It requires companies to do something else in addition to salaries", "There needs to be something special about the company that the individual will want to come and work for you."

A third open code referred to an expressed need for specific competencies/profiles that are required to be able to cope with the nature of the industry. Rapid change requires adaptability and flexibility: "The IT environment changes so quickly, you need people that are adaptable, flexible, can cope with the change", "The technology has moved so fast that the people haven't necessarily acclimatised, the business mechanisms, thinking patterns haven't adjusted", "Globalisation requires that you have to be adaptive, extremely adaptive", "They want a particular mould, and we're battling in the market". In this environment, 'poaching' appears common, whereby organisations pay higher than average salaries in order to entice staff away from existing employers. This contributes to the notion of a 'sellers' market, where candidates have high salary expectations, possibly due to their knowledge of the skills shortage. In an industry where profit is a key driver, the impact of this can be significant in terms of its contribution to employment costs: "Your competitors start paying a premium for attracting people or taking people away from you ... all of a sudden your cost of employment escalates", "If it's a black person and he's good and they want them, they get them, they pay them anything", "... a salary war ... they're all paying slightly more, so it's just lifting the salaries and salary bands", "Where the skill set is there, the salaries and expectations of those candidates is just way out of what we are willing to pay". This is particularly rife among Employment Equity (EE) staff, where the skills shortage is particularly hard felt.

A fourth open code referred to the challenges pertaining to EE staff in particular. All participants were faced with the issue of finding 'black' skill at senior professional and management levels. Whilst many of the participants' companies were introducing initiatives to address the shortage of EE skill, this is not having an immediate effect in terms of rectifying the problem, but is rather seen as a longer term solution. Participants also felt that this problem was added to by the fact that the industry had an historical problem in this respect, as EE issues were not previously addressed with any degree of commitment: "It's probably not addressing diversity or employment equity at the level that we want", "We really struggle to get the demographics right", "We are now developing capability for employment equity candidates ... but they are not adequate, especially when you move to senior levels", "This was an industry ... that was fairly isolated from transformation perspectives", "Clearly the IT industry has been dominated by males and mainly white males".

The fifth open code referred to leadership development which is also linked to the skills shortage and EE challenges, as organisations are not able to find the skill externally in the market, nor are the initiatives being put in place to deliver leaders as quickly as they would like them to: "We're weak in a strong pipeline of people coming through", "We have a need to grow and develop leaders". Combining the above five features produced a second axial code that characterised the South African IT industry as one where a serious skills shortage exists, especially with reference to so-called 'black skills' to comply with BEE and EE requirements. This is particularly relevant at senior professional and leadership levels where development initiatives are not producing results soon enough. This has led to a market where there is fierce competition for skilled staff and where employees, well aware of their scarcity, are in a position to demand ever higher remuneration in a market that is strongly profit driven.

\section{Strategic requirements for $H R$}

A third sub-theme emerged relating to a strategic requirement for HR. This sub-theme developed from two related open codes. The first referred to the need to grow and maintain profitability which, coupled with the legislative demand to transform, was regarded as a very challenging balancing act: "That's the challenge - to meet the labour laws challenges, to meet the BEE stuff and so on, but at the same time meet our targets and grow at the rate that they want us to grow". "It's to try and balance your strategic endeavour with also trying to transform your business." The second referred to the participants' acknowledgement of a move towards a stronger focus on the people element and a possible greater requirement for HR type activities: "So the new focus is on people management". "... how to in fact build a people-based culture and what does that in fact mean", "... there's a realisation that there's a need for HR ... we need to nurture our people".

The second core theme related to the role of HR against the background of these industry-specific organisational challenges.

\section{Theme 2: Role of HR}

Within the second core theme a further three sub-themes, each consisting of a number of related open codes, were identified. These three sub-themes related to (1) the fact that HR roles have changed, (2) the nature of the emerging roles and (3) the challenge for existing HR practitioners to actually effect change.

\section{Changed HR role}

When asked what the effect of the organisational challenges was on the HR function, the participants started describing the various roles that they were fulfilling. In the first place there was a clear acknowledgement that the role of HR had changed significantly from what it was in the past, and that there was a need to continue evolving: "HR's role has totally changed. If I think about the role that I fulfilled five years ago versus the role I fulfill today, it's very different", "HR has to operate differently", "Gone are the days that you could say I am taking on a cheap resource ... that HR has become a 'cushy' job, it has become an extremely demanding role", "In the next two years (HR) are going to have radically changed their jobs, everyone of them, radically, from what they were trained to do to what we now require of them". The role of HR was previously seen as being rather detached from the actual business, and having limited impact in terms of the outcomes of initiatives: "... used to say, well hey, we tried this and whatever ..." "We just used to just always dream up programmes and say $\mathrm{OK}$, well we can do that, now we have to take so many things into consideration". The role is now perceived as being far more complex, requiring a different type of individual to fulfill it successfully. It requires a more senior professional who is able to manage the increased complexity: "... it's definitely more complex in terms of the demands", "They are all highly professional people", "It forces you to employ people at that level, whereas in the past you could have probably got away with less", "... it's definitely scaled in terms of the level of individual that you need in $H R$, 'cos it's a more strategic role".

\section{Nature of emerging role}

The first role to emerge was that of a business partner, who works very closely with management, who understands the nature and direction of the business, and who is essentially an operational manager and leader in their own right: "... closer to the actual leadership team ... HR's working much closer to the business today", "So HR has become really an operationally involved executive, sitting at strategy, but also making sure 
strategy is executed", "Your job is the whole time to be with managers, the whole time the managers and people". "It's a requirement that they understand the place in history where they're at, and the direction of the business, and the direction of the global business", "They now are in an operational zone ... suddenly this HR person actually has a line function which includes the development of a whole pile of things, a new procurement mechanism, a new enterprise development issue, social responsibility", "If you have no influence, that is: it's all about leadership and persuasion, at a strategic level, then you're dead in the water". This role is facilitated by the use of outsourcing and technology, which enables HR to move away from transactional based work and to focus more on strategic contributions. There is recognition that, for the move to a business partner to take place, the day-to-day transactional HR work needs to be removed: "We're also outsourcing more than we did in the past, the whole aim is obviously to be able to focus more on core HR consulting", "Technology is obviously assisting hugely ... if I look at transactional stuff, we just don't do it, it's all automated ... everything's on-line", "The systems do most of the stuff and the admin is minimal". One of the participants had also moved toward a shared service centre concept in order to facilitate the role of business partner: "We started implementing a shared services centre, which actually helps to gradually migrate some of the transactional HR ... so that HR can ... provide more of the strategic consulting service".

A second role that emerged was that of HR as a generalist. This does not imply that HR professionals should have a broad but shallow knowledge, but rather that they are required to have an in-depth, expert knowledge of a broad range of HR issues, as well as some which may be outside the realm of traditional HR: "If you look at a generalist role it's able to deal with a variety of issues from compensation to recruitment. In our case, we can't get deeply involved with each topic, you need to understand what the issues are, you need to come up with a strategy, you need to either source someone in or you need to get a task team together and focus on that and move on", "This job here is a generalist job, it's actually a General Manager's job ... it's got a human resource element to it, but actually it's a General Manager of the business job", "You have to be a knowledge expert, you've got to have an exceedingly good knowledge of all these various things ... you are expected to be yes, a Jill or Jack of all trades, but you are expected to be a master of them all, as well", "You expect people to be multi-skilled". The ability to operate outside of traditional HR, using non-traditional HR skills, appears to be becoming increasingly important, and could be linked to the increased complexity of the function: "The skills sets that they're now required to have ... are dramatically different, and in fact they're business skills, not HR skills", "... but it is a requirement today that you suddenly are a public relations person", "If you hired me today here, you'd be looking for a lawyer", "Your specialisation is a global specialisation", "Not one of them have had outside HR experience, and that's a problem", "I think one needs a lot of organisational savvy", "You've got to be good at negotiating". The multinational participants also expressed the need to be able to operate in a global context: " $A$ person has responsibilities locally, but they are part of a functional team at a regional level", "... worldwide standards that's got to be complied with, irrespective of our labour laws".

A third role was that problem-solver, specifically in the area of people relations, whereby $\mathrm{HR}$ is expected to manage the relationship between management and employees, especially the difficult issues, so that management is freed up to focus on the business side of things: " ... .try and develop a magic wand that can take these issues away from business", "That's your job, motivating, encouraging, resolving problems", "You have this mediator role quite a lot of times where the staff member will come to you and says he or she is unhappy about this issue", "I deal with the issues that go wrong, and the issues that nobody knows what to do with, so I deal with the exceptions ... so they see me as a corporate problem-solver".
In terms of problem-solving, a number of participants also described their role as a 'counselor', a function that is linked to the high levels of stress and burnout: "People coming to you, they can't take this anymore or whatever, and you've got to, you know, talk to them and try and get them motivated again, try and resolve the issue", "You would have to spend a lot of time talking to people and you cannot give guarantees, so you've got to kind of placate and you've got to talk to people, counsel even", "I spend a lot of time in personal counseling conversations with people", "It is, I believe, attributed to levels of stress". Some, however, viewed their role almost as the antithesis of this. It appears that in difficult times, or when dealing with difficult situations, HR can become the cause of stress and tension, almost an enemy against the people they are supposed to look after: "You are always seen as an area that could be regarded as an enemy of people", "... people that have got to be sacked".

The role of problem-solver is also evident in the relationship between line management and $\mathrm{HR}$, which was perceived as a difficult one. Whilst HR is working closer to management, there is a perception that HR gets called in to do the 'dirty work', the tasks that are unpleasant and not particularly enjoyed by managers. There is also a perception that line management lack an understanding of what HR actually does, and the amount of work that is required on an ongoing basis: "You cannot approach business without HR being an absolute partner-in-crime ... who is the bad wolf who will assist line managers to get rid of people, or to discipline people or to get people to toe the line? It's HR, together with line", "... line managers will position HR as the enemies who are there to cull people, if you can put it that crudely, and they love us on the one hand, but they hate us on the other hand", "You don't have a great deal of support base 'cos there's no real supporters around you", "What we also did was to reposition $H R$, which I think is very important, it needs to be repositioned appropriately within the organisation to say ... what role does HR fulfill now?", "I don't think that the business really understands the amount of work that goes into an $H R$ department ... the perception is you hire and you fire ... and why is my medical aid wrong?"

\section{Challenge for HR practitioners}

Despite the challenges implied by the roles described above, there was a perception that this was an opportunity for HR to elevate itself and take up a position of greater importance: "It must be one of the most exciting HR departments there can be", "... you are actually looking at opportunities to shine, that you've never been given before ... anybody can take those opportunities and do much more with their lives", "HR, the role of $H R$, can become the doorkeeper rather than the backroom boy", "I can see that business partnership role being much stronger than 5 years ago, which is good for me as an HR professional. I mean that's where we always said that's where it needs to go", "I think actually for those who grow into the challenge it's going to be great, because it gives them a whole new developmental thrust if you like, they've got a whole new job thing and it's a more senior job that an HR job used to be". However, one participant cautioned that the existing HR people may not be able to make this change: "Not everyone is going to change, not everyone's capable and I'm not sure they want to, to be frank".

The core theme discussed immediately above related to the role of HR against the background of the industry-specific organisational challenges discussed earlier. The third core theme that emerged referred to the emotional effects of both the context within which they work, and the impact of their roles as HR professionals on the individual participants.

Theme 3: Effect of HR roles on individuals

In describing the HR role the participants freely spoke about the effects on individuals in these roles, often reflecting on the effects upon themselves personally. This lead to the third and final core theme: Effects of HR roles on individuals operating within HR. The following sub-themes emerged: 


\section{Inherent conflict}

Inherent conflict in the role of an HR professional emerged strongly as a sub-theme, particularly in terms of what the role is expected to deliver. As mentioned previously, $\mathrm{HR}$ is often expected to do the unpleasant tasks, involving dismissing or disciplining employees, and yet they are also expected to be the ones who look after employees' interests; roles that are at opposite ends of the spectrum. The nature, or personality, of the person who goes into HR, was also seen as possibly at odds with the expectations of the role. This conflict often also creates a moral or ethical dilemma for the HR practitioner: "Who is the bad wolf who will assist line managers to get rid of people, or to discipline people or to get people to toe the line? HR ... that places a tremendous amount of conflict in the minds of HR practitioners", "You're meant to be nice and presentable and sweet ... and at the same time you're also meant to be tough, and ... stamp your foot and make things happen ... there's a conflict, a disconnect", "The roles ... fundamentally different from the personality sets, not necessarily the skills sets", "When I go to church I sometimes question myself whether the things that I'm expected to do at work are aligned with my Christian beliefs".

\section{Job pressures}

The second sub-theme related to the high pressure which the participants felt themselves to be under. This pressure stemmed from having to keep abreast of current developments and having to continually update and expand their own skill sets: "I must make sure that I am up to speed with the business, I must keep up with the change and also be very proactive", "You've got to make sure that you read widely, that you spend enough time researching things", "We've got to give and be the source of competitive advantage ... so you have to spend vast amounts of time on reading, studying the law, having a look at where you can save costs", "I have long ago realised I needed to expand my skill sets". The nature of the work also adds to the pressure, as does the sheer volume of work they are expected to complete: "You've always got problems ...", "The people that you hire within an HR team ... have to be able to not get irritated when they're multi-tasking and someone walks in ... and they have to drop everything, and they do need to handle high levels of stress and pressure", "... there's a lot of work, a lot, lot, lot of work". The ability to deliver results also adds to the high pressure: "HR performance is measured", "If you're not delivering competitive advantage, they say what's wrong with you ...", "a broad concept, value-add ... performance, you do what you say you are going to do".

\section{Long hours and burnout}

In order to cope with the demands of the role, the participants are working long hours: "There's just not enough hours in the day, that's the reality, so it forces you to spend vast amounts of time after hours ...", "I have to burn the candle at both ends and in the middle". One participant attributed this to the actual industry itself, postulating that long hours were an expectation, if one wanted to be successful: "I think most IT companies are the same... If you want to make it, you've got to be seen to be working late, and you've got to be seen to work on the weekends. It's an expectation". The demands and the associated long hours are creating high levels of stress, and the use of the word 'burnout' was common. Work-life balance was an issue, where work appears to be taking precedent over personal and leisure time: "... which puts a hell of a lot of demand and strain on an HR practitioner", "Many HR practitioners, senior people, suffer from burnout because of these demands", "I'm starting to draw on my own personal energy as opposed to my professional energy", "You've got to make personal sacrifices. The sacrifices of family, of your own leisure", "I've seen people who are involved in these ER practices and sustained that kind of pressure for eight or nine months, and then all of a sudden collapse", "It goes back to the burnout sort of issue, where you're working long hours and you're just slogging and slogging and slogging and it just doesn't seem to come to an end". Whilst there is an awareness of the likelihood of burnout, the reality appears to be that little is done to prevent it. Dissatisfaction, despondency and often resignation are the end result: "I think they sometimes get despondent because they get no recognition, I think that's very difficult for them", "You just cannot, you just can't continue to work and work and work like that, eventually somewhere the rope's got to break, it's got to snap", I've had people resign because they said they just can't take the pressure".

The three core themes identified above (1) industry-specific organisational challenges, (2) role of HR and (3) effects of HR roles on individuals in HR are discussed next.

\section{DISCUSSION}

The findings from the study confirmed what was evident in the literature regarding the nature of the IT industry generally. The industry was indeed described as fast-paced, dynamic, and characterized by rapid change. An emphasis on performance was also evident, both financially and individually. Despite the reliance on people and their skills, it was not viewed as an industry where people management played a strong role. High demands, with little support, seemed to result in high levels of stress and burnout.

Research participants placed specific emphasis on the current skills shortage. The industry was described as small, with limited skills capacity and the current demand for skills is clearly outweighing the supply, resulting in fierce competition, or a 'talent war'. This leaves companies in a position where they have to do more than just pay people equitable salaries; they need to find 'intangible' attraction measures that distinguish them from their competitors. Ggubule (2006) concurred with this, arguing that traditional rewards and benefits are regarded as standard in a 'seller's market'. Whilst the skills shortage is real, companies are also very specific about the type of individual that they recruit, as a certain type of person, an almost unique 'profile', is required to survive in the industry. Adaptability and flexibility were identified as key competencies in this regard.

In this environment of a 'talent war' poaching is rife, especially among Employment Equity (EE) candidates. The lack of available EE skills is particularly seen at professional and managerial level, resulting in the payment of higher and higher premiums. In an industry that was traditionally dominated by white males, many initiatives have been put in place, and may well bear fruit in years to come, but they are not addressing the problem as it stands now. The skills shortage leads to 'poaching', where companies identify staff at their competitors and approach them directly with the aim of enticing them away, usually on the basis of better jobs and higher salaries. As more and more companies do this, companies have to fight to attract the best resources, whilst at the same time, try to retain their existing resources from the attraction efforts of other companies.

BEE was also confirmed as a challenge in the industry, particularly among multinationals, who have limited options in terms of selling shares in the business. Compounding this is the need to maintain profitability, amidst a delicate balancing act in terms of meeting both legislative and shareholder requirements. Figure 1 captures most of the above scenario graphically, and highlights the apparent need for an increased focus on peoplerelated activities.

The findings also confirmed the apparent need for HR to change the way it operates, specifically in terms of its strategic focus. This increased complexity has resulted in the need for more senior, professional people to fulfill the role and within this context, specific roles emerged.

The first role, namely that of a business partner, corresponded with the views strongly advocated in the cited literature. It was suggested that HR is working closer to 
organisational leadership and management and is more involved at both a strategic and operational level. Leadership and influence were mentioned as key capabilities that HR requires in order to fulfill their role as business partners, or establish what Bear (2004) terms "credibility". Referring to the change agent role specifically cited in the literature review earlier, both focus groups viewed this role as an integrated part of the business partnership role (as opposed to Ulrich's (1997) view thereof as a separate change agent role). Participants felt that in such a rapidly changing environment, keeping up with changes meant keeping in touch with the business and ensuring that required changes were translated into action.

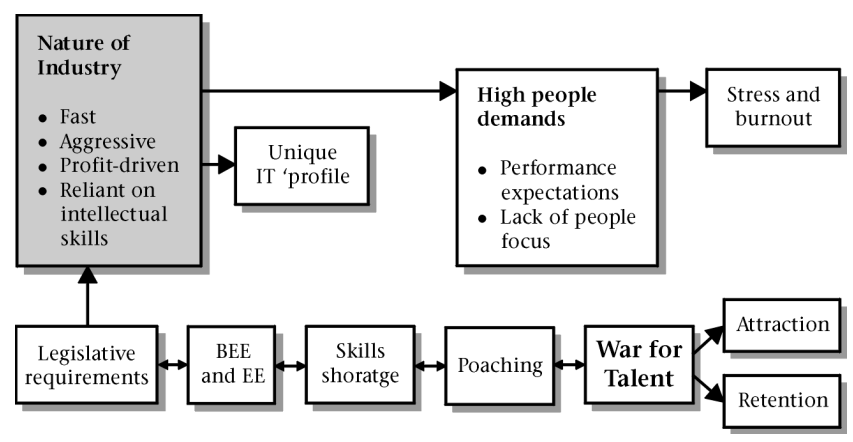

Figure 1: Industry challenges

The second role evident from the literature, namely that of a generalist, was also confirmed through the research. However, in line with the views of Ulrich and Brockbank (2005), the study confirmed the need for HR to remain an expert in its own field, possibly implying even higher levels of competence and skill. The participants felt that they needed to have a broad, yet in-depth, range of knowledge pertaining to all matters relating to $\mathrm{HR}$, as well as matters not traditionally perceived as HR related, such as public relations, general management, and globalisation.

The third role identified from the research namely that of a problem-solver was not distinctly specified in the literature. It may well fit into the role of change agent, which is described as assisting organisations in facilitating change. However, the participants described a more specific role whereby they are expected to solve a range of people issues, either for or with line management. A sub-role identified in this theme was that of a counselor. This may be similar to Ulrich and Brockbank's 'employee advocate' role (2005), which is seen as someone caring, listening, and responding to employee needs. Whilst the 'employee advocate' role involves proposing better, more fair policies relating to employees, the research suggested that this is possibly more of a psychological counseling role, largely necessitated by the high levels of stress and burnout in the industry.

The problem-solver role, however, often implies a degree of inherent conflict, as $\mathrm{HR}$ is expected to handle the tough, unpleasant issues, such as disciplinary matters and retrenchment, which often cause employees' distress. The old view of HR being there to hire and fire is still evident, as HR gets called in by line management when difficult actions need to be taken against employees. HR is clearly in a difficult position as they can be caught between employees and management. They are required to be there for employees, but can also be perceived as 'enemies' when labour action is required.

With reference to HR's administrative role, the research findings concurred with Gaines-Robinson and Robinson's (2005) view that, certainly at a senior HR management level, there was a complete move away from transactional-based work. This was facilitated by the use of technology, outsourcing and shared service centres which freed up time to focus more on the business partner role. The above findings are graphically depicted in Figure 2 below.

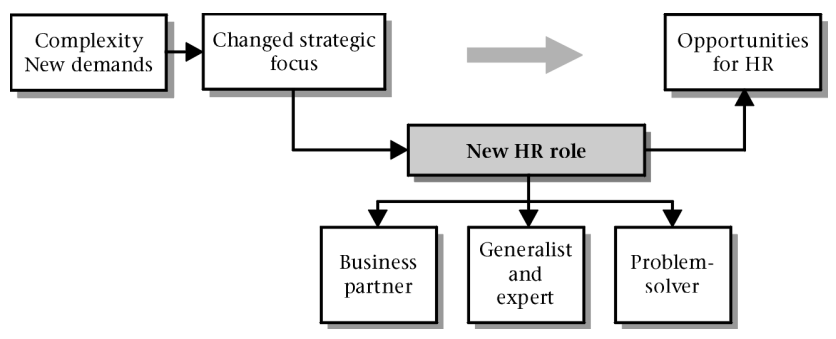

Figure 2: Changed HR role

Whilst the implied changes for HR in the IT industry is apparent from Figure 2, the research did indicate that many opportunities exist in this regard, and that the time has possibly never been better for HR to elevate itself to become an integral part of the business. There was a cautionary note, however, that not all HR people would necessarily be able to transition into this 'new' role. The key factor in this regard was believed to be the possible emotional impact or consequences that the industry and the specific HR roles within that industry, could have on individuals in those roles. Conflict was identified as an inherent part of the job. There was also a concern that the traditional people-oriented HR person might not be able to cope with these demands. Furthermore, the HR role was seen as one of constant high pressure. This arose from the need to keep oneself at the forefront of recent developments, both in the HR field and in the IT industry itself, as well as the nature of the work, which is often highly emotive. The sheer volume of work was also seen as a contributory factor, as was the need to deliver quality output. This resulted in HR people working long hours, with a negative impact on work-life balance and burnout as a real possibility. Bear (2004) argued that burnout could also be caused by the "increased scrutiny" on, and the higher expectations of HR people. The scope of the effects of all the above-mentioned changes on individuals in these HR roles, are depicted in Figure 3.

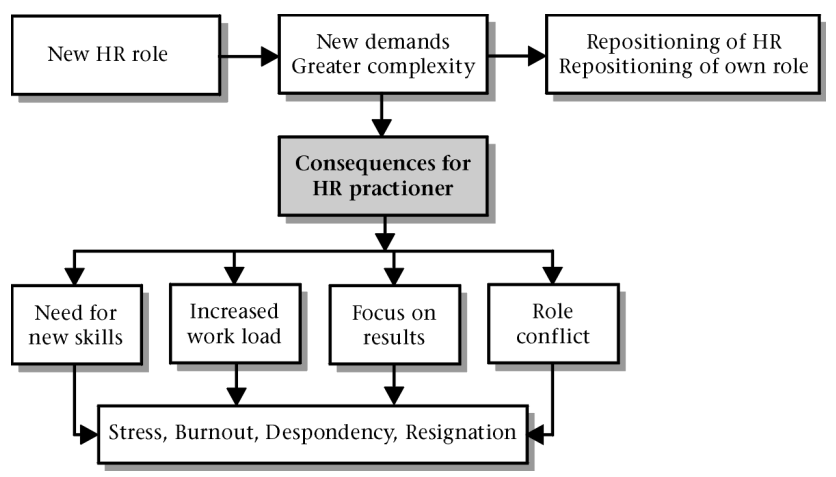

Figure 3: Effect of HR roles on individuals

The nature of the IT industry, the changed role of HR within this industry and the effect of both of these on individuals operating within HR have to be taken note of by both the industry and the HR professionals operating within this industry.

\section{CONCLUSION AND RECOMMENDATIONS}

The IT industry is, and will probably remain, a key industry in modern day economies worldwide. However, it is evident that the industry is faced with many people-related challenges, 
especially the attraction and retention of uniquely skilled employees, and the management of high levels of stress and burnout. It is against this background that HR is believed to be in a position to make a meaningful contribution, provided it can reposition itself as a business partner, a generalist and $H R$ expert at the same time, and a problem-solver across many contexts. The industry is hugely reliant upon human capital and there appears to be a huge need for human resource interventions, at both a management and employee level. This does indeed create opportunities for HR within the industry in terms of becoming significant contributors to the business. Whether this opportunity will be taken up, however, seems to depend largely on the credibility of HR individuals themselves, and their ability to develop their skills in time to meet the demands and thereby change the perception of what HR is about, and what it can do.

The findings of the study have implications for many stakeholders. Firstly, key decision-makers in the IT industry have to accept that the industry is one that attracts intelligent, professional and hard-working people. Yet, the industry is rife with stress and burnout, which may partly be as a result of the lack of focus on people management and people issues. The industry needs to recognise that its core competitiveness stems primarily from its people, and therefore look at initiatives to adequately address its people issues.

The issue of stress and burnout across all levels of employees is of particular concern. It is a known fact that stress has a negative impact on performance, at an individual and organisational level (Muchinsky, 2003). All companies within the industry are encouraged to assess their current levels of stress and burnout and develop initiatives to combat this. Another crucial issue is the need to attract and retain staff which is currently primarily addressed at individual company level. Consideration should be given to address the problem at industry level. Developing basic levels of employee benefits and actively marketing the industry as an employer of choice could be some of the ways to promote the industry among potential job-seekers, even attracting skills from other industries. An analysis of what other industries do in this respect could offer valuable insights.

The lack of a long-term view of the skills shortage in the IT industry should also be a major concern to all stakeholders. Whilst technological advances and the associated skill sets that go with them are, to a certain degree, hard to predict, the industry appears to be dealing with the problem at a micro-level rather than a macro-level. Many companies are trying to develop skills within their own organisations and only a few are collaborating at a higher level on joint initiatives to solve the bigger problem of building up a national skills pool. The culture of 'poaching' that appears to be the order of the day was seen by most participants to be ultimately harmful in the long run; yet, the demands of the business were such that they were forced to continue.

Secondly, key decision-makers in the IT industry have to recognise the need for highly qualified, senior, professional and experienced HR people to operate at a strategic level and to deal with the many people-related challenges unique to the industry. This will have implications for the recruitment and selection of HR people in future, where the competency profiles will have to reflect the raised expectations of these roles. These competencies should ideally include an understanding of business strategy, an in-depth knowledge of all HR areas, as well as skills in the areas of problem-solving, negotiation and counseling.

Organisations in the IT industry should furthermore realise that the current lack of budgetary support is forcing HR people into a situation where they are trying to do everything themselves, with negative consequences for both the organisation and themselves. In an industry with such high expectations and tight financial controls (and where people are not a key focus), spending money on people-related issues appears to be a major problem. Ironically, spending money on HR issues could lead to higher productivity and hence better performance. If money were available, HR practitioners could bring in some of the specialist skills that they themselves lack, thereby providing services so desperately required. An example would be the use of Employee Assistance Programmes (EAP's) where counseling services are made available to employees at the company's cost. This would enable employees to have professional support and, at the same time, take some pressure off HR who could then focus on other issues.

Thirdly, HR practitioners in the IT industry should reflect on the serious long-term consequences of them finding neither the time, nor the resources, to focus on long-term planning. Whilst reactively dealing with the effects of change, very little is done to increase the core competencies of adaptability, flexibility and change readiness, either in themselves, or in their employees. In this respect, it was evident from the research that, whilst all the participants experienced similar problems, a lack of communication between HR professionals in the industry exists. One possible solution would be to create a forum where practitioners could come together and share ideas and issues in a safe, confidential manner. Cross-skilling and training initiatives to address areas of development could also be a function of the forum. Many senior HR people are operating in the industry, and the use of coaching and mentoring could have beneficial effects, especially in many smaller organisations that often have only one HR person. The support that such an initiative could provide could also help to alleviate some of the stress experienced by HR professionals.

Fourthly, academic institutions offering training for HR practitioners should take note of the emerging roles and align their curricula to fully prepare students for these. In this process, specific high-level skills and competencies (such as individual counseling skills that are more adequately addressed in the curricula of industrial psychologists) should be clearly identified to ensure that adequate training is provided.

Despite all the inherent challenges alluded to above, the HR professionals interviewed all seemed excited and positive about the future. They saw scope and opportunities for HR to make a more strategic and valuable contribution, provided that they could face and meet the demands that the largely changed expectations placed on them.

Limitations of the study and suggestions for further research This study was conducted solely within the IT industry, and should therefore not be made applicable to other industries without reserve. Furthermore, selected participants were at a senior level in their organisations, either in a managerial or director position; the views of more junior HR people could differ as they are probably more involved at an operational level, and slightly distanced from the more strategic levels of the business and the organisations' management structure. Junior employees are probably also less exposed to difficult situations or decisions, which may lead to differences in their views of the HR environments within which they operate. An extended study incorporating inputs from other levels of HR staff could therefore possibly add value. Given the nature of the IT industry, it would furthermore be interesting to assess the effect of the industry on other functional groups within it (for example, technical staff). In addition, a similar study among HR professionals operating in another industry would also be of interest, and would furthermore aid in ascertaining possible generalisability of the findings. Finally, the views of the senior management from the participating companies could possibly shed some light on the relationship between management and $\mathrm{HR}$, and possibly explain some of the conflict pertaining to different roles and expectations. 
Of particular value would be further research to establish means to quantify the contribution of HR in real terms. Whilst many participants referred to the high expectations of HR, little reference was made as to how these are actually measured. The development of an HR measurement tool could possibly assist in determining the 'real' bottom line contribution, thereby elevating the position of HR by acknowledging its contribution in a quantifiable manner. Further exploration of each identified core and subtheme could also be of interest. The issue of stress and burnout is obviously of major importance, and further research could help to understand (1) the causes and consequences of stress and burnout, (2) implications for companies, HR and individual employees and (3) possible remedial actions. A study on the skills shortage would also be beneficial to determine (1) the current and future skills requirements, (2) the future supply of potential IT employees as evidenced by registrations at training providers and (3) the relevance of IT training curricula currently being taught. This study could also be supported by a critical assessment of the Mathematics and Science training at school level, and the impact thereof on future IT employees. Finally, the development of employee effectiveness and change readiness programmes for the IT industry specifically, could also be of great value.

Given the importance of the IT industry globally and the unique HR-related challenges in the industry specifically, focused and continued research in many areas are probably not only desirable in the short term, but crucial in the long term. It is hoped that this study highlighted some of the areas requiring urgent attention, from both an industry and HR point of view.

\section{REFERENCES}

Aamodt, M.G. (2004). Applied Industrial/Organizational Psychology. Belmont, CA: Wadsworth/Thomson.

Babbie, E. \& Mouton, J. (2005). The practice of social research. Cape Town: Oxford University Press.

Bear, D.J. (2004). The evolving HR function. Books $24 \times 7 . c o m$ : Human Resources Institute.

Berg, B.L. (1995). Qualitative research methods for the social sciences. Boston, MA: Allyn \& Bacon.

Boudreau, J.W. \& Ramstad, P. (2003). Strategic HRM measurement: From justifying $\mathrm{HR}$ to strategic talent leadership. In M. Effron, R. Gandossy \& M. Goldsmith (Eds.). Human resources in the $21^{\text {st }}$ century. Hoboken, NJ: John Wiley.

Brockbank, W. (2003). Convergence of HR: Leadership and change management. In M. Effron, R. Gandossy \& M. Goldsmith (Eds.). Human resources in the 21st century. Hoboken, NJ: John Wiley.

Burden, F.J. (2006). The development of an organisational redesign model: A South Africa case study. (Unpublished doctoral thesis). Johannesburg: University of Johannesburg.

Burrows, T. (2005). HR's BEE question: Organic growth or bought skills? ITWeb Brainstorm, March 2005, pp. 108-109.

Burrows, T. (2006). The IT skills cupboard is bare. ITWeb Brainstorm, April 2006, pp. 72-73.

Burton, D. (2000). The use of case studies in social science research. In D. Burton (Ed.). Research training for social scientists. London: Sage.

Business Day Management Review (2005). Is HR friend or foe? Depends on who's asking the question. Business Day, August 2005, pp. 10-11.

Denzin, N. K. \& Lincoln, Y. S. (2003). Collecting and interpreting qualitative materials (2nd ed.). Thousand Oaks, CA: Sage.

Draft Black Economic Empowerment Charter for the ICT sector. May 2005. http://ictcharter.org.za

Esterberg, K.G. (2002). Qualitative methods in social research. Boston, MA: McGraw-Hill.
Evans, C. (2003). Managing for knowledge: HR's strategic role. Books $24 \times 7$.com: Butterworth-Heinemann.

Fletcher, P.A.K. (2005). From personnel administration to business-driven human capital management - the transformation of the role of HR in the digital age. In H.G. Gueutal \& D.L. Stone (Eds.). The brave new world of eHR: Human resources in the digital age. Books $24 \times 7 . c o m$ : JosseyBass.

Gaines-Robinson, D. \& Robinson, J.C. (2005). Strategic business partner: Aligning people strategies with business goals. Books $24 \times 7$.com: Berrett-Koehler.

Gqubule, T. (2006). The real retainer. Financial Mail, 187 (1), p. 50.

Green, M.E. (2002). Internal human resources consulting: Why doesn't your staff get it? Public Personnel Management. 31 (1), pp. 111-119.

Guba, E.G. \& Lincoln, Y.S. (1994). Competing paradigms in qualitative research. In N.K. Denzin \& Y.S. Lincoln (Eds.). Handbook of qualitative research. Thousand Oaks, CA: Sage.

Henson, R. (2005). The next decade of HR - trends, technologies, and recommendations. In H.G. Gueutal \& D.L. Stone (Eds.). The brave new world of eHR: Human resources in the digital age. Books $24 \times 7$. com: Jossey-Bass.

Hosking, A. (2006). Business strategy and HR. HR Future, March 2006.

Hunter, I. \& Saunders, J. (2005). Transforming HR: How to get shared services, outsourcing and business partnership to deliver what you want. Books $24 \times 7$.com: Thorogood.

Jeffay, J. \& Bicos, S.K. (2003). Managing for execution: HR delivery imperatives for the 21st century. In M. Effron, R. Gandossy \& M. Goldsmith (Eds.). Human resources in the $21^{\text {st }}$ century. Hoboken, NJ: John Wiley.

Kaye, B., Scheef, D. \& Thielfoldt, D. (2003). Engaging the generations. In M. Effron, R. Gandossy \& M. Goldsmith (Eds.). Human resources in the 21 ${ }^{\text {st }}$ century. Hoboken, NJ: John Wiley.

Lawler, E.E., Ulrich, D., Fitz-enz, J. \& Madden, J.C. (2004). Human resources business process outsourcing: Transforming how HR gets its work done. Books 24×7.com: John Wiley \& Sons.

Lessard, B. \& Baldwin, S. (2003). Netslaves 2:0: Tales of "surviving" the great tech gold rush. Books $24 \times 7$. com: Allworth Press.

MacDonald, J.R. (2003). Profession at a crossroads. In M. Effron, R. Gandossy \& M. Goldsmith (Eds.). Human resources in the $21^{\text {st }}$ century. Hoboken, NJ: John Wiley.

Marshall, C. \& Rossman, G.B. (1999). Designing qualitative research (3rd ed.). Thousand Oaks, CA: age.

Mouton, J. (2001). How to succeed in your masters and doctoral studies. Pretoria: Van Schaik.

Muchinsky, P.M. (2003). Psychology applied to work (7th ed.). Belmont, CA: Thomson Wadsworth.

Neuman, W.L. (2000). Social research methods: Qualitative and quantitative approaches. Needham Heights, MA: Allyn \& Bacon.

Rothwell, W.J., Prescott, R.K. \& Taylor, M.W. (1998). The strategic human resource leader. Books 24×7.com: Davies-Black Publishing.

Rubin, H.J. \& Rubin, I.S. (1995). Qualitative interviewing: The art of hearing data. London: Sage.

Sartain, L. (2003). Getting extraordinary results from ordinary people. In M. Effron, R. Gandossy \& M. Goldsmith (Eds.). Human resources in the 21 $1^{\text {st }}$ century. Hoboken, NJ: John Wiley.

Saunders, M., Lewis, P. \& Thornhill, A. (2003). Research methods for business students (3rd ed.). Essex, England: Pearson Education.

Schurink, W. (2003). Qualitative research in management and organisational studies with reference to recent South African research. SA Journal of Human Resource Management, 1 (3), pp. 2-14. 
Schurink, W. (2005). Qualitative research design Part I. Lecture notes for post-graduate study school at University of Johannesburg, 17-21 January 2005.

Strauss, A. \& Corbin, J. (1990). Basics of qualitative research. Newbury Park, CA: Sage Publications.

Swanepoel, B. (Ed.), Erasmus, B., Van Wyk, M. \& Schenk, H. (2003). South African human resource management: Theory and practice (3rd ed.). Lansdowne, Cape Town: Juta.

Ulrich, D. (1997). Human resource champions. Boston, MA: Harvard Business School Press.

Ulrich, D. \& Brockbank, W. (2005). The HR value proposition. Boston, MA: Harvard Business School Press.
Ulrich, D. \& Smallwood, N. (2003). What's next for the people function? A missing link for delivering value. In M. Effron, R. Gandossy \& M. Goldsmith (Eds.). Human resources in the $21^{\text {st }}$ century. Hoboken, NJ: John Wiley.

Van der Westhuizen, C., Van Vuuren, L.J. \& Visser, D. (2003). Human resource management as a profession in South Africa: Practitioners' perspectives. SA Journal of Human Resources Management, 1 (2), pp. 1-12.

Vegter, I. (2005). Telkom unleashed. ITWeb Brainstorm, Dec 04/Jan 05, pp. 27-29.

Wheatley, M. (2003). When change is out of our control. In M. Effron, R. Gandossy \& M. Goldsmith (Eds.). Human resources in the $21^{\text {st }}$ century. Hoboken, NJ: John Wiley. 